\title{
Microhardness and Young's Modulus of a Bonding Resin Cured with Different Curing Units
}

\author{
Monica YAMAUTI ${ }^{1,2}$, Toru NIKAIDO ${ }^{1}$, Masaomi IKEDA ${ }^{1}$, Masayuki OTSUKI ${ }^{1}$ and Junji TAGAMI ${ }^{1,2}$ \\ ${ }^{1}$ Section of Cariology and Operative Dentistry, Department of Restorative Sciences, Graduate School, Faculty of Dentistry, \\ Tokyo Medical and Dental University, 5-45 Yushima, 1-Chome, Bunkyo-ku, Tokyo 113-5489, Japan \\ ${ }^{2} 21^{\text {st }}$ COE Program, Frontier Research Program on Molecular Destruction and Resconstruction of Tooth and Bone at Tokyo \\ Medical and Dental University \\ Corresponding author, E-mail:monica.ope@tmd.ac.jp
}

Received August 18, 2004/Accepted September 9, 2004

\begin{abstract}
This study evaluated the microhardness and Young's modulus of a photocurable bonding resin, Clearfil SE Bond (SE), cured with four curing units at different distances. The curing units used were: Candelux (Quartz-tungsten halogen), Lux-O-Max (Blue light emitting diode), Arc-light (Plasma-arc), and Rayblaze (Metal halide). Discs of bonding resin were prepared using vinyl molds and were photocured at the top surface with light tip at three different distances (contact, 2 and 4 mm). After 24 hours of storage in water at $37^{\circ} \mathrm{C}$, the specimens were sectioned into halves, embedded in epoxy resin, and polished. The microhardness and Young's modulus of this bonding resin were measured using a nanoindentation tester. Six specimens were prepared for each group. The data was statistically analyzed using two-way ANOVA test and Tukey multiple comparison test $(\mathrm{p}<0.01)$. The microhardness of SE was affected by light source and distance, as was Young's modulus. Candelux and Rayblaze presented the highest hardness and Young's modulus results. Both properties presented high values when the curing unit tip was maintained in contact with the irradiated surface. Increasing the distance between the curing unit tip and the irradiated surface decreased the hardness and Young's modulus of SE.
\end{abstract}

Key words: Bonding resin, Nanoindentation test, Microhardness

\section{INTRODUCTION}

The quartz-tungsten halogen lamp has been the popular, most frequently used light-curing unit (LCU) to polymerize resin materials. However, this LCU has shown some drawbacks. The most common defects detected in this LCU are related to the degradation of bulb and light reflector, broken filters, breakdown of optical fibers, and tip damage ${ }^{1)}$. This damage then leads to a decrease in light output over time, which could compromise the polymerization of resin materials, and consequently, the clinical behavior of the restoration. Moreover, curing with quartz-tungsten halogen is time-consuming because of the long irradiation time required to cure each layer of resin composite ${ }^{2)}$.

To overcome these drawbacks of traditional quartz-tungsten halogen lamps, some new LCUs have been introduced in the market. A recent development for dental clinical applications is the plasma-arc curing light. The manufacturers of this kind of light claim faster curing time than quartz-tungsten halogen, hence reducing chairside time. Due to the greater light intensity, plasma-arc curing lights help to enhance the speed of polymerization ${ }^{3)}$. Besides, these curing units have a spectral output that is more intense at certain wavelengths, compared to quartz-tungsten halogen lights ${ }^{4}$. Blue light emitting diode LCUs have been developed, which claim curing to be as good as quartz-tungsten halogen ${ }^{5)}$. These
LCUs present some advantages such as nondegradation of bulbs (blue light emitting diode lamp does not have any bulb), easy handling (portable, battery operated, cordless) ${ }^{6)}$, and longer lifetime than quartz-tungsten halogen ${ }^{7)}$. The metal halide technology, which has been successfully developed to polymerize indirect composites $^{8)}$, is presented here with a prototype to apply its properties to clinical use. The manufacturer of this curing unit also claims fast curing.

Several studies in our laboratory have been developed to examine bonding between the different adhesive systems and dentin. It was observed that quartz-tungsten halogen and metal halide LCUs presented the best bond strength results after 24-hour storage in water, when compared to blue light emitting diode and plasma-arc curing LCUs ${ }^{9}$.

However, regardless of the type of curing unit used, power density decreases as the distance between the tip and the irradiated surface increases ${ }^{10,11}$. Power density also decreases as it passes through the material $^{12)}$. This is a very important factor to consider in clinical practice due to the deep cavities that need to be restored with resin composite materials. In our laboratory, a previous study was developed based on an adhesive, Clearfil SE Bond (Kuraray Medical Inc., Tokyo, Japan), cured with different LCUs. It was observed that as the thickness of resin composite increased, bond strength of the adhesive to bovine dentin decreased ${ }^{13)}$. 
Hardness is a measure of a rnaterial's strength and has been used as an indirect method to measure the depth of cure of composite materials ${ }^{14)}$. Hardness correlates well with the degree of conversion although it cannot be used to predict the degree of conversion $^{14)}$. Young's modulus is an important property that must be determined as the stiffness of resin-based materials can vary and do not fully match those of natural teeth ${ }^{15}$. Polymerization shrinkage, an inherent property of resin materials, produces stresses, which can interfere with the adhesive interface, enamel and dentin substrates. A relatively thick bonding layer of $50-150 \mu \mathrm{m}$ has been effective in leveling the mismatch of modulus values at the restoration-tooth interface ${ }^{16)}$.

Many reports abound on the properties of resin composite restorative materials. However, very few papers are available on the polymerization of bonding resin. It is important to evaluate the polymerization of bonding resin as long as resin tags contribute to the adhesion between resin and tooth substrates. According to a theoretical model of tensile bond strength of resin to dentin developed by Pashley et $a l{ }^{17)}$, the total bond strength of a resin is the sum of the strength of resin tags plus the strength of resin infiltrating non-tubular porosity plus the strength of resin due to surface adhesion. The authors reported that the contribution of resin tags to the theoretical tensile bond strength significantly increased as the ultimate tensile strength of resin increased. In turn, the strength of resin tags may vary depending on the type of adhesive, its degree of polymerization, and the cross-sectional area of the tags. Hansen and Swift ${ }^{18)}$ and Crim $^{19)}$ have reported on the effect of pre-polymerization of bonding resin prior the place- ment of restorative resin on microleakage. Both studies demonstrated less microleakage when a bonding resin was cured before placement of the restorative material. Therefore, for a good sealing, the bonding resin should be well polymerized. Additionally, with strong bond strength, the effect of stress developed due to polymerization shrinkage could be minimized ${ }^{20)}$.

Therefore, the purpose of this study was to evaluate the microhardness and Young's modulus of a bonding resin cured with four LCUs at three different distances between the tip and the irradiated surface.

\section{MATERIALS AND METHODS}

The material used in this study was the bonding resin of Clearfil SE Bond (Kuraray Medical Inc., Tokyo, Japan). Its basic formulation is shown in Table 1.

Four light curing units were used to polymerize the bonding resin: Candelux (CDX, Quartz-tungsten halogen, J. Morita, Kyoto, Japan), Lux-O-Max (LOM, Blue light emitting diode, Akeda Dental, Lystrup, Denmark), Arc-Light (ARL, Plasma-arc, Air Techniques, New York, USA), and Rayblaze (RBZ, Metal Halide, Moritex, Tokyo, Japan). The irradiation time is shown in Table 2; the manufacturers' instructions were followed. The wavelengths of all the light curing units (Fig. 1) were measured using Spectrometer USR-40 (Spectroradiometer type USR-40V-01, Ushio, Japan, \#01070016). Power density was also measured with a digital hand-held radiometer (Jetlite Light Tester, J. Morita, CA, USA, \# 9061727).

Table 1 Material, lot number, and basic formulation

\begin{tabular}{lcc}
\hline Material, Code, and Manufacturer & Lot Number & Basic formulation (bonding resin) \\
\hline Clearfil SE Bond & 00161A & MDP; Bis-GMA; HEMA; Hydrophobic dimethacrylate; \\
& & dl-CQ; N,N-Diethanol-p-toluidine; Silanated colloidal silica
\end{tabular}

SE (Kuraray Medical, Tokyo, Japan)

MDP: 10-metacryloyloxydecyl-dihydrogen phosphate

Bis-GMA: bisphenol-A diglycidylmethacrylate

HEMA: 2-hydroxy-ethylmethacrylate

$\mathrm{CQ}$ : camphorquinone

Table 2 Curing units, codes, manufacturers, light source, and irradiation time

\begin{tabular}{ccccc}
\hline $\begin{array}{c}\text { Curing unit and code } \\
\text { (manufacturer) }\end{array}$ & Light source & $\begin{array}{c}\text { Power density } \\
\left(\mathrm{mW} / \mathrm{cm}^{2}\right)\end{array}$ & $\begin{array}{c}\text { Irradiation time } \\
(\mathrm{sec})\end{array}$ & $\begin{array}{c}\text { Total energy } \\
(\mathrm{J})\end{array}$ \\
\hline $\begin{array}{c}\text { Candelux - CDX } \\
\text { (Morita, Japan) }\end{array}$ & $\begin{array}{c}\text { Quartz-tungsten } \\
\text { halogen }\end{array}$ & 707 & 10 & 1.12 \\
$\begin{array}{c}\text { Lux-O-Max - LOM } \\
\text { (Akeda, Denmark) }\end{array}$ & $\begin{array}{c}\text { Blue light emitting } \\
\text { diode }\end{array}$ & 98 & 10 & 0.15 \\
$\begin{array}{c}\text { Arc-Light - ARL } \\
\text { Plasma-arc }\end{array}$ & 1134 & 3 & 0.54 \\
$\begin{array}{c}\text { Rayblaze - RBZ } \\
\text { (Moritex, Japan) }\end{array}$ & Metal halide & 1625 & 3 & 0.77 \\
\hline
\end{tabular}




\section{Spectral of irradiance}
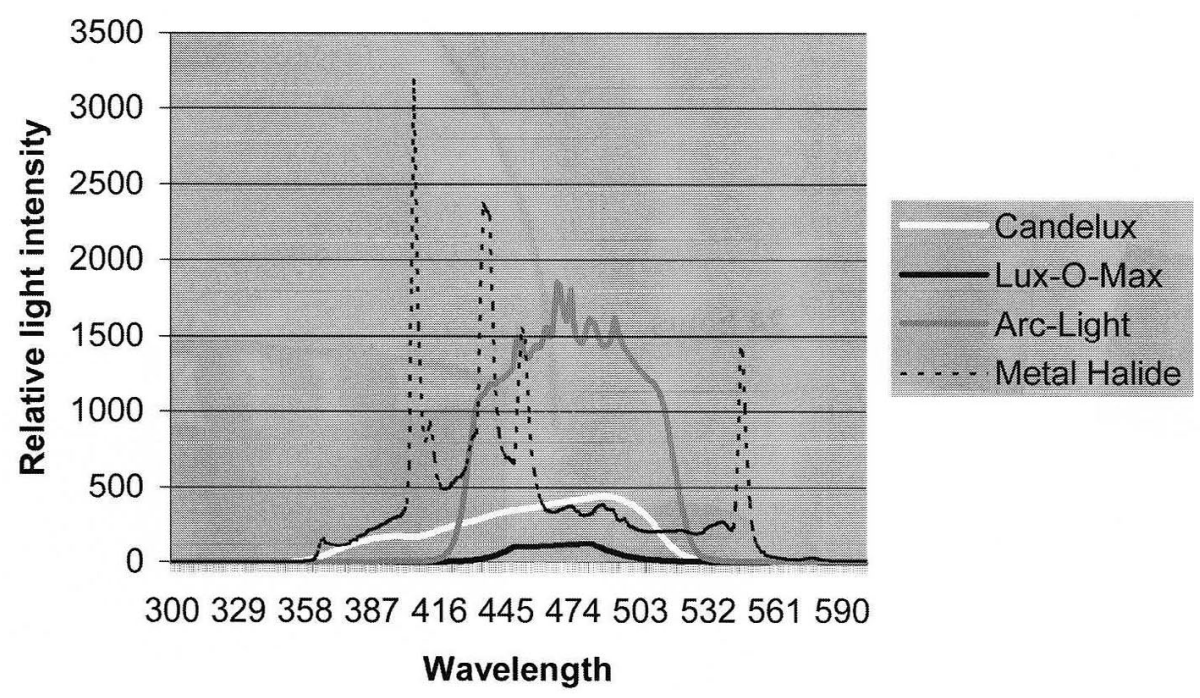

Fig. 1 Wavelength distribution.

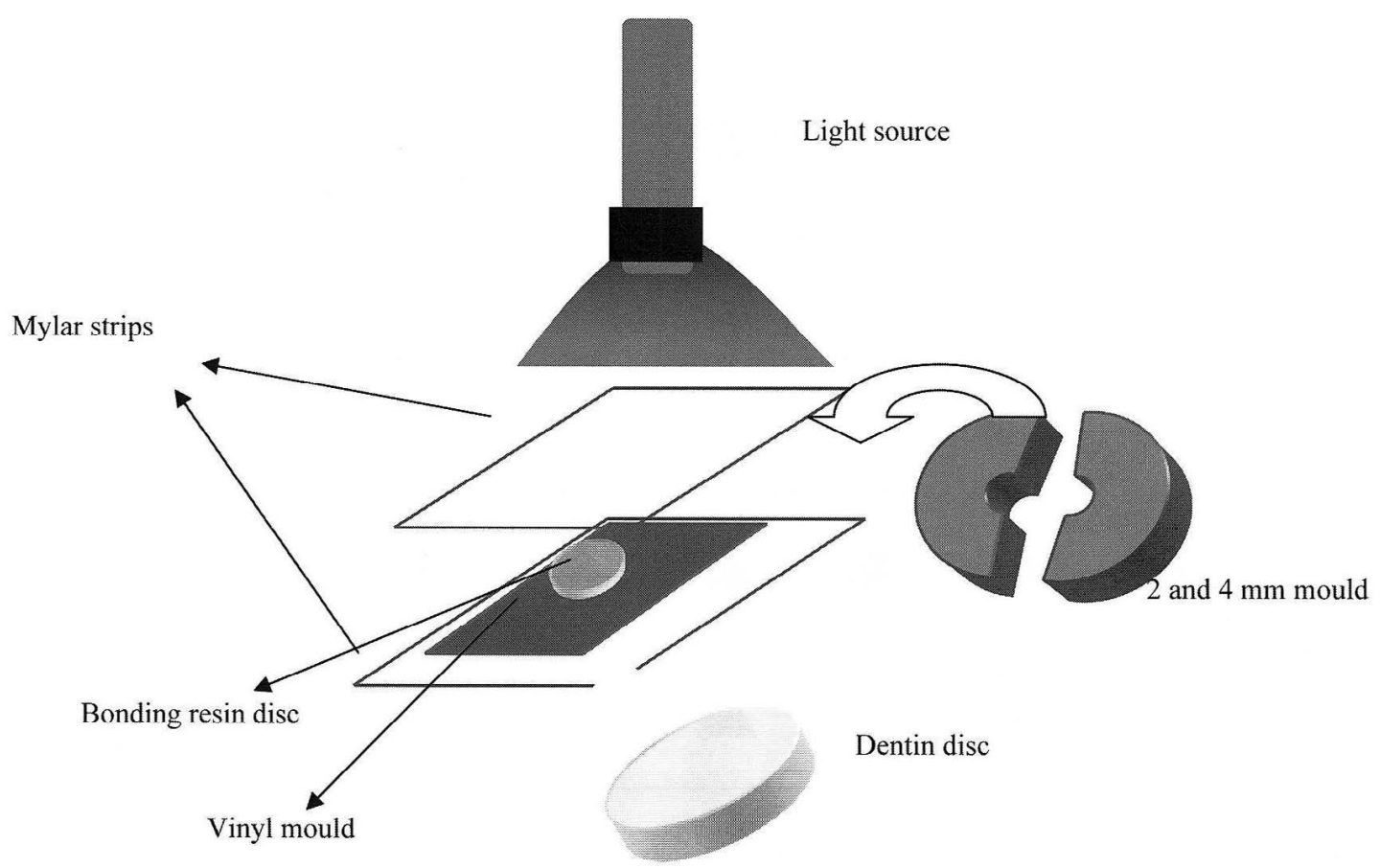

Fig. 2 Specimen preparation scheme.

Fig. 2 illustrates the specimens' preparation procedure. Holes ( $4.5 \mathrm{~mm}$ in diameter) were prepared in a vinyl tape (Yamato, Tokyo, Japan) of approximately $0.4-\mathrm{mm}$ thickness. Dentin discs of 2-mm thickness were prepared from extracted human third molars. These teeth were sectioned with a diamond saw (Buehler, IL, USA) under copious water and slow speed. The dentin discs were polished with Si-C papers \#600 to produce standardized smear layer, and they served as the background as in clinical situations. A Mylar strip (Lumi Strip, Inoue Attachment Co., Tokyo, Japan) was placed on the dentin, and over this was the vinyl tape matrix. The bonding resin $\mathrm{SE}$ was poured on the hole, and 

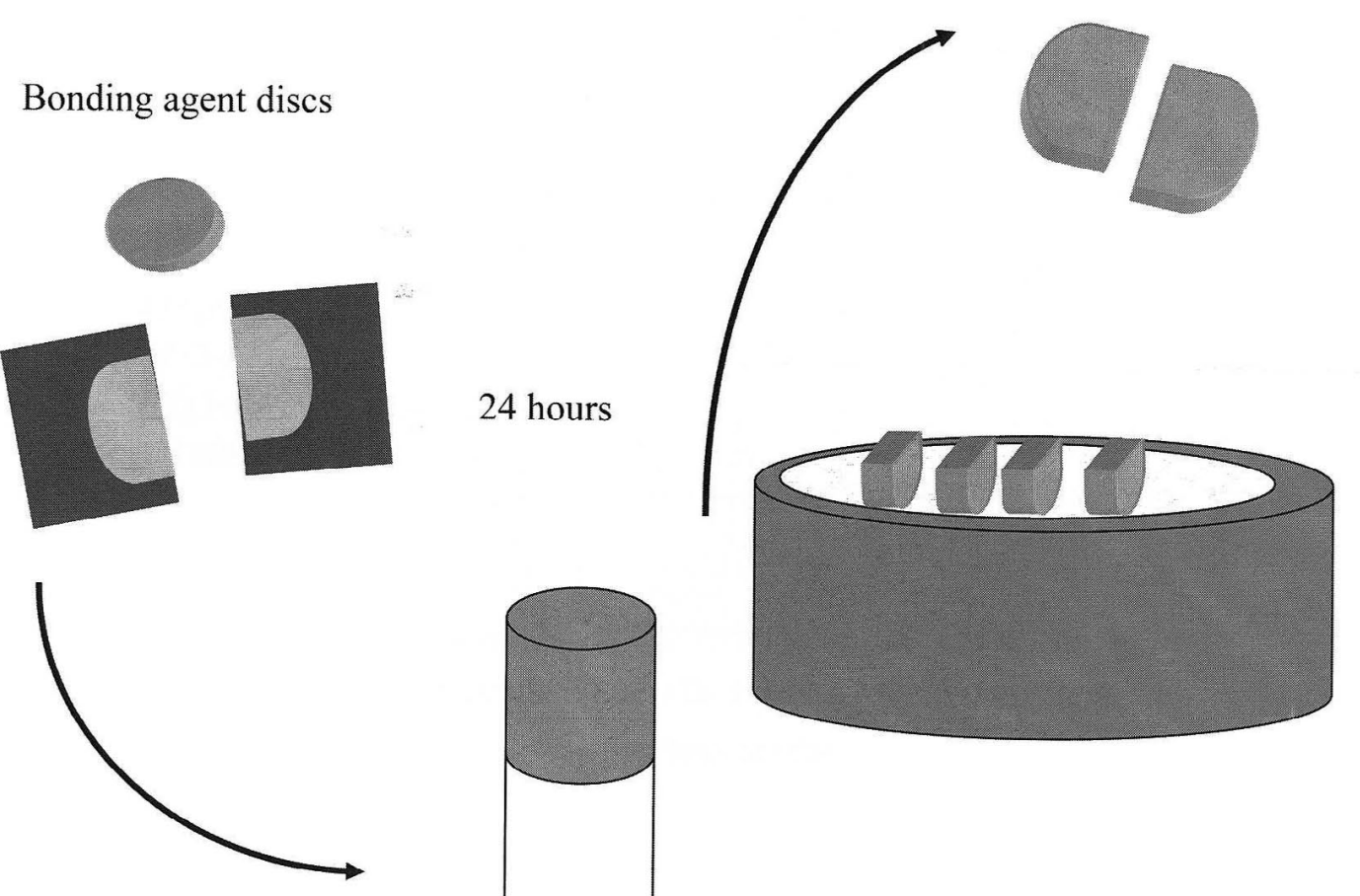

Nanoindentation tester

$5 \mathrm{gf}$

Fig. 3 Embedding the cross-cut specimens in epoxy resin.

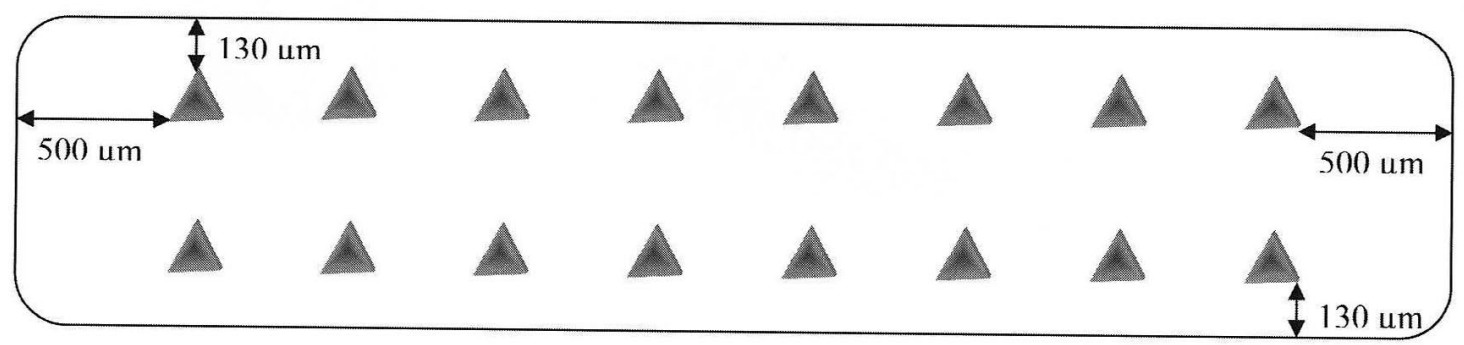

Fig. 4 Representative illustration of nanoindentations in the cross-cut surface of the bonding resin disc.

another Mylar strip was placed on this surface to make it flat. The four curing units were used according to the manufacturers' instructions to polymerize the bonding resin (Table 2).

To polymerize the bonding resin, tips of the curing units were maintained at three different distances from the surface: contact $(0 \mathrm{~mm}), 2 \mathrm{~mm}$, and $4 \mathrm{~mm}$. Six bonding resin discs were prepared for each curing unit at each predetermined distance between the tip and the irradiated surface. There were 72 specimens in total.

Immediately after preparation, the specimens were immersed in tap water and stored for 24 hours at $37{ }^{\circ} \mathrm{C}$ in darkness. Subsequently, they were sectioned into halves for in-depth assessment of microhardness and Young's modulus. Therefore, rectangular cross-section surfaces were obtained, embedded in epoxy resin (EPON 815, Shell Chemical Co., 
Nisshin EM Co., Tokyo, Japan) (Fig. 3), and left for 24 hours until the epoxy resin was cured. The specimens were polished using $\mathrm{Si}-\mathrm{C}$ papers up to 1500 -grit (Marumoto Struers KK, Tokyo, Japan) followed by cotton cloths up to $1-\mu \mathrm{m}$ diamond paste (Struers, Ballerup, Denmark). Care was taken to ensure that the disc surfaces were flat and parallel to each other.

The discs were fixed to a metal stage with cyanocrylate adhesive (Konishi Co., Tokyo, Japan). Parallelism between disc and stage surfaces was checked visually. Microhardness and Young's modulus were measured using a nanoindentation tester (Elionix ENT-1100, Elionix Inc., Tokyo, Japan) under a load of $0.05 \mathrm{~N}$. Elionix ENT-1100 is a depthsensing, computer-controlled instrument with a Berkovich indentor - which is a three-sided pyramid diamond probe. The main body of ENT-1100 is mounted on a vibration isolator and placed within an environmental isolation enclosure with a temperature controller.

Sixteen measurements were obtained for each specimen (Fig. 4). The first measurement was made approximately $500 \mu \mathrm{m}$ from the specimen's lateral sides and $130 \mu \mathrm{m}$ from the upper and lower surfaces of the cross-sectional disc. A distance of $500 \mu \mathrm{m}$ was maintained between each measurement. The average of 16 measurements obtained for each specimen was then used in its microhardness and Young's modulus calculations. The microhardness and Young's modulus values of SE were calculated based on the index of Elionix indentor. This is an index modified from the index reported by Oliver and Pharr ${ }^{21)}$.

All the microhardness and Young's modulus data of SE were analyzed using two-way ANOVA (SigmaStat version 2.03, SPSS, Chicago, IL, USA). Differences among the groups were assessed using Tukey multiple comparison tests (SigmaStat version 2.03, SPSS, Chicago, IL, USA). Statistical significance in all analyses was set in advance at 0.01 probability level.

\section{RESULTS}

Table 3 shows the mean and standard deviation of the microhardness and Young's modulus of SE cured by different LCUs. Two-way ANOVA revealed significant differences $(p<0.001)$ among the LCU and tip distance groups for microhardness and Young's modulus.

In the case of microhardness, Tukey multiple comparison tests indicated that increasing the tip distance from the irradiated surface decreased the microhardness value $(p<0.001)$. There was no interaction between both factors. When the tip was in contact with the irradiated surface, SE presented the highest values compared with the tip at 2- and 4-mm distance from the surface. There were no significant differences between the microhardness values with the tip at 2 and $4 \mathrm{~mm}$ from the irradiated surface of SE. Regarding LCUs, there were no significant differences between the microhardness values of $\mathrm{SE}$ when it was cured with either CDX or RBZ. These values were significantly higher than those of LOM and ARL, which were not statistically different from each other.

In the case of Young's modulus, both factors (LCU and tip distance) affected the results $(p<0.001)$. There was a significant interaction between them. In other words, the effect of LCU depended on which distance the light was maintained from the irradiated surface. The Young's modulus varied with tip distance, decreasing as the distance increased. When the tip was in contact with the irradiated surface, there were no significant differences among the Young's modulus of SE cured with RBZ $(7.61 \pm 0.03 \mathrm{GPa}), \mathrm{CDX}(7.49 \pm 0.12 \mathrm{GPa})$, and ARL $(7.26 \pm 0.12 \mathrm{GPa})$, which were significantly higher than that of LOM $(6.41 \pm 0.48 \mathrm{GPa})$. At 2 -mm distance, there were no significant differences among the groups, except between CDX $(7.09 \pm 0.33 \mathrm{GPa})$ and ARL $(6.64 \pm 0.40 \mathrm{GPa})$. When the light tip was maintained at $4 \mathrm{~mm}$ from the surface, there were no significant differences between RBZ $(6.92 \pm 0.05 \mathrm{GPa})$ and ARL $(6.57 \pm 0.07 \mathrm{GPa})$, and between ARL and CDX $(6.39 \pm 0.09 \mathrm{GPa})$. At this distance, LOM presented the lowest Young's modulus value $(5.62 \pm 0.13$ $\mathrm{GPa}$ ), which was significantly different from the other groups.

\section{DISCUSSION}

Hardness has been widely used as an indirect method to measure the depth of cure of resin-based materials. Although the degree of conversion appears to be

Table 3 Nanohardness and Young's modulus of SE. Values are expressed as means (standard deviations), $\mathrm{n}=6$. Mean values with different superscripts are significantly different $(\mathrm{p}<0.001)$

\begin{tabular}{c|cc|cc|cc|cc}
\hline & \multicolumn{2}{|c|}{ CDX } & \multicolumn{2}{c|}{ LOM } & \multicolumn{2}{c}{ ARL } & \multicolumn{2}{c}{ RBZ } \\
& $\begin{array}{c}\text { Hardness } \\
\left(\mathrm{Kgf} / \mathrm{mm}^{2}\right)\end{array}$ & $\begin{array}{c}\text { Young's modulus } \\
(\mathrm{GPa})\end{array}$ & $\begin{array}{c}\text { Hardness } \\
\left(\mathrm{Kgf} / \mathrm{mm}^{2}\right)\end{array}$ & $\begin{array}{c}\text { Young's modulus } \\
(\mathrm{GPa})\end{array}$ & $\begin{array}{c}\text { Hardness } \\
\left(\mathrm{Kgf} / \mathrm{mm}^{2}\right)\end{array}$ & $\begin{array}{c}\text { Young's modulus } \\
(\mathrm{GPa})\end{array}$ & $\begin{array}{c}\text { Hardness } \\
\left(\mathrm{Kgf} / \mathrm{mm}^{2}\right)\end{array}$ & $\begin{array}{c}\text { Young's modulus } \\
(\mathrm{GPa})\end{array}$ \\
\hline Contact & $23.49(0.31)^{\mathrm{a}}$ & $7.49(0.12)^{\mathrm{A}}$ & $19.93(2.09)^{\mathrm{c}}$ & $6.41(0.48)^{\mathrm{B}}$ & $20.55(0.71)^{\mathrm{C}}$ & $7.26(0.12)^{\mathrm{A}}$ & $23.59(0.32)^{\mathrm{a}}$ & $7.61(0.03)^{\mathrm{A}}$ \\
$2 \mathrm{~mm}$ & $21.78(0.95)^{\mathrm{b}}$ & $7.09(0.33)^{\mathrm{C}}$ & $18.42(1.31)^{\mathrm{d}}$ & $6.83(0.27)^{\mathrm{C}, \mathrm{D}}$ & $18.71(1.53)^{\mathrm{d}}$ & $6.64(0.40)^{\mathrm{D}}$ & $20.99(0.35)^{\mathrm{b}}$ & $6.75(0.03)^{\mathrm{C}, \mathrm{D}}$ \\
$4 \mathrm{~mm}$ & $20.89(0.23)^{\mathrm{b}}$ & $6.39(0.09)^{\mathrm{G}}$ & $17.48(0.68)^{\mathrm{d}}$ & $5.62(0.13)^{\mathrm{F}}$ & $18.97(0.58)^{\mathrm{d}}$ & $6.57(0.07)^{\mathrm{E}, \mathrm{G}}$ & $22.36(0.05)^{\mathrm{b}}$ & $6.92(0.05)^{\mathrm{E}}$ \\
\hline
\end{tabular}


the most sensitive test for depth of cure, hardness correlates well with the degree of conversion of resin materials $^{14,22)}$.

The nanoindentation test consists in a special hardness testing method, which can measure very small structures using precise indentations with diameters of only a few micrometers and at loads of only a few Newtons. The indentation depth is monitored in situ during loading and unloading. As a result, microhardness and Young's modulus can be calculated from the load-displacement curve, and be not biased by visual assessments as with the conventional microhardness testers ${ }^{23)}$. This method has been widely used to measure the hardness and Young's modulus of resin-dentin bonding areas ${ }^{23)}$, adhesive resins $\mathrm{s}^{24)}$, and biological hard tissues ${ }^{25-28)}$.

Two-millimeter thick human dentin discs were used as background materials to simulate the background color of dental substrate to which dental adhesive systems are adhered in clinical situation. In addition, Fan et al. ${ }^{29)}$ have shown that hardness values of resin composites differed when black and white backing conditions were used. Black backing decreased the hardness of resin composites while white backing promoted the degree of conversion of the lower surface of resin composites. The whitereflecting backing made available more light to polymerize the lower surface, as in in vivo situations ${ }^{29)}$.

It has been reported that the mechanical properties of bonding resin were substantially affected by storage in water ${ }^{30)}$. Water has an adverse effect on polymers, as hydrolysis occurs passively. Carrilho et $a l^{31)}$ have reported that water-free oil storage allowed adhesive systems specimens to achieve better degree of conversion than those tested after 24 hours of immersion in water. Additionally, for light-cured resin-based materials, the polymerization reaction gradually continues even in darkness - a process known as post-irradiation hardening ${ }^{32,33)}$. When specimens are immersed in water soon after preparation, this immersion could cause an immediate water uptake that plasticizes the polymer ${ }^{31)}$ and this could adversely affect post-irradiation reaction.

In clinical situations, water vapor is present in the oral environment as well as in the working environment. Musanje and Darvell ${ }^{34)}$ have demonstrated that resin composites can absorb this water vapor. Additionally, dentin is a naturally wet substrate. Dentine tubules contain fluid that could affect the polymerized bonding resin.

Concerning microhardness values, the highest values were obtained when the tip was maintained in contact with the irradiated surface regardless of which LCU was used. The microhardness value decreased as the distance increased, and there were no significant differences in results be it at the $2-\mathrm{mm}$ or 4-mm distance.
Usually, power density decreases as light passes through the air and through the thickness of composite material ${ }^{35)}$. Thus, the power density of LCU decreases as the light tip moves away from the irradiated surface ${ }^{36)}$. Physically, power density as a function of distance from the light source follows an inverse-square relationship. However, Rueggeberg and Jordan $^{37)}$ have demonstrated that when light exits the light tip, its decrease in intensity does obey this law for distances measured between 0 and 10 $\mathrm{mm}$. Instead, the decrease occurres due to light divergence at an angle. The latter was dependent on the ratio of the indices of diffraction of air and that of the composition of light tip $^{37}$.

In microhardness results, two distinct groups could be observed: CDX/RBZ versus ARL/LOM. The first group presented higher microhardness values, which could be attributed to LCU characteristics and composition of SE. $\mathrm{CDX}$ and $\mathrm{RBZ}$ presented largespectrum irradiance (Fig.1) and the total energy (1.12 $\mathrm{J}$ and $0.77 \mathrm{~J}$, respectively) was sufficient to activate SE's photo-components. According to the manufacturer, SE contains camphorquinone $(\mathrm{CQ})$ and another photoinitiator - which is not disclosed. In the ARL/LOM group, although ARL presented higher power density $\left(1134 \mathrm{~mW} / \mathrm{cm}^{2}\right)$ and higher total energy $(0.54 \mathrm{~J})$ than LOM, no significant differences were observed in the microhardness of $\mathrm{SE}$ cured with both LCUs. These results could be attributed to the wavelength distribution of ARL. The wavelength distribution of ARL was not as wide as those of CDX and RBZ (Fig. 1), which yielded the highest hardness values. Although the wavelength distribution of ARL was larger than that of LOM, it is speculated that the unknown photoinitiator of $\mathrm{SE}$ could not be activated within ARL's range. It could be further speculated that the wavelength range of ARL could not completely activate SE's photocomponents. In the case of LOM, the low hardness results $\left(19.93+2.09 \mathrm{Kgf} / \mathrm{mm}^{2}\right)$ could be attributed to its narrow spectrum (Fig. 1) and low power density $\left(98 \mathrm{~mW} / \mathrm{cm}^{2}\right)$, thus leading to a poorer polymerization than those obtained with other LCUs. In addition, the peak of LOM's wavelength distribution was around $460 \mathrm{~nm}$ - which essentially activated CQ only but not the other unknown photo-component of SE.

The microhardness results of this study were in accordance with other studies conducted to evaluate the mechanical properties of resin-based materials cured with different light sources. Christensen et $a l{ }^{38)}$ analyzed several properties of various resin composites cured with different LCUs. According to their study, the modulus seemed to be highly affected by resin formulation rather than other factors such as LCU. The authors examined the Young's modulus of six resins cured with 12 LCUs. There were no differences among the LCUs, but there were 
significant differences among the different resin formulations. Micro-filled resin had the lowest modulus, and an autocured resin had a modulus that was significantly higher than all the other lightcured resins.

Quartz-tungsten halogen LCUs are very popular and widely used in clinical practice due to their relatively inexpensive price and maintenance. They have good power density and are able to emit a broad wavelength range of usable lights that cure different materials ${ }^{39)}$. Additionally, quartz-tungsten halogen has proven to be able to cure materials at different depths ${ }^{40)}$. When it comes to polymerizing composite materials, metal halide lights have performed well in previous studies conducted with indirect resin composite materials ${ }^{8,41,42)}$. However, more studies are needed to evaluate the potential of metal halide for clinical use to polymerize direct composite materials and adhesive systems. When materials were cured using plasma-arc curing lights, studies have shown that the resultant materials rendered inferior properties such as lower surface hardness and poor polymerization. The main reasons cited in these studies for such unsatisfactory results were namely short curing time and material formulation ${ }^{43-49)}$. Hofmann et $a l^{45)}$ demonstrated that the suitability of plasmaarc light for a particular material depended on the photoinitiator it contained. Studies conducted with blue light emitting diode LCUs have demonstrated conflicting results. Some studies showed that the performance of blue light emitting diode was as good as quartz-tungsten halogen in terms of hardness and depth of cure ${ }^{7,50,51)}$. Others yielded inferior properties when the materials cured with blue light emitting diode LCUs were compared to those results obtained with quartz-tungsten halogen lights ${ }^{52-54)}$. Despite the different findings, all authors agreed that blue light emitting diode LCUs have a great potential for clinical use as long as the light intensity be improved.

Concerning Young's modulus, it also decreased as distance increased. In other words, the bonding resin SE became less stiff (i.e., lower modulus) as the tip distance increased. Despite this observed trend, there was a great variance among the modulus values with the use of different LCUs. When the tip was in contact with the irradiated surface, only LOM presented significantly lower Young's modulus than the other LCUs. This was attributed to the low power density and narrow wavelength range of LOM, which meant that it could not optimally cure SE. As a result, monomers remained unconverted and the bonding resin became more flexible. At $2 \mathrm{~mm}, \mathrm{CDX}$, LOM, and RBZ had no significant differences in the Young's modulus results as well as LOM, RBZ, and ARL. When tip distance from the irradiated surface increased, the elasticity of SE decreased for all LCUs, except for LOM - which had an increase in Young's modulus value. No explanation could be offered for this increase with LOM.

At 4-mm tip distance, RBZ and ARL produced more rigid specimens than CDX and LOM. It is suggested that, in this case, power density could have a significant effect on the development of Young's modulus. Hence, high power density LCUs (i.e., RBZ and ARL) produced more rigid specimens than CDX and LOM. In effect, LOM presented the lowest Young's modulus value. This was because LOM had the lowest power density and a very narrow wavelength distribution that probably could not activate SE's photo-components.

Takahashi et al. ${ }^{24)}$ evaluated the relationship between bond strength to dentin and the mechanical properties of adhesive resins. However, no correlation was found between hardness or Young's modulus and bond strength. Nevertheless, in clinical situations, Young's modulus is a very important factor when considering its relation to the stresses at the adhesive interface ${ }^{55}$. In clinical situations, the adhesion of adhesive system to human substrate is achieved through the use of primer and bonding resin - as illustratively demonstrated by Van Meerbeek et al. ${ }^{56)}$ using different microscopy techniques. Yoshida et al. ${ }^{57)}$ reported that some functional monomers, such as 10-MDP (which is one of SE's components), could also chemically bond to hydroxyapatite of dental hard tissues. Some studies have reported that the primer affects the mechanical properties of bonding resins. According to Hotta et $a .^{58)}$, hardness and tensile strength of adhesive/ primer mixtures were lower compared to the results of bonding resin used alone. Griffiths and Watson ${ }^{59)}$ reported that viscosity difference between primer and adhesive could also affect bonding to dentin.

A great deal of research has demonstrated a strong correlation between resin material's formulation and adhesion ${ }^{38,60,61)}$. In other words, it is desirable to obtain a good match between material formulation and LCU characteristics in order to achieve good adhesion. Several materials that contain photoinitiators other than $\mathrm{CQ}$ have been introduced to the market. As such, it is necessary to assess the polymerization effect on these materials by different LCUs. Hirabayashi and Imai ${ }^{62)}$ and Hirabayashi ${ }^{63)}$ have reported that different photoinitiators led to different levels of polymerization of PMMA/MMA resin.

The results of this study should be considered with care. Only one brand of bonding resin was used in this study. The results cannot be extrapolated and compared with other materials due to differences in chemical formulation. Additionally, bonding resin alone was used in this study, whilst in clinics it is always used with primer. Therefore, further studies with other materials, photoinitiators, and LCUs need to be conducted in order to establish 
some clinical guidelines.

\section{CONCLUSIONS}

Within the limitations and conditions of this study, the following conclusions may be arrived at:

- Different curing units and different irradiation distances affected the hardness and Young's modulus of SE;

- In general, as the irradiation distance increased, the hardness and Young's modulus of SE decreased.

\section{ACKNOWLEDGEMENTS}

The authors thank Prof. Karl-Heinz Kunzelmann for his invaluable critique and advice, as well as review of this paper.

The 21st COE Program, Frontier Research Program on Molecular Destruction and Resconstruction of Tooth and Bone at Tokyo Medical and Dental University, supported this work.

\section{REFERENCES}

1) Barghi N, Berry T, Hatton C. Evaluating intensity output of curing lights in private dental offices. J Am Dent Assoc 1994; 125: 992-996.

2) Caughman WF, Rueggeberg FA, Curtis JW Jr. Clinical guidelines for photocuring restorative resins. J Am Dent Assoc 1995; 126: 1280-1282,1284,1286.

3) Millar BJ, Nicholson JW. Effect of curing with a plasma light on the properties of polymerizable dental restorative materials. J Oral Rehabil 2001; 28: 549-552.

4) Aw TC, Nicholls JI. Polymerization shrinkage of composite resins using plasma-arc photocuring. Gen Dent 2001; 49: 473-479.

5) Takahashi N, Fujibayashi K, Ishimaru T, Kohno A. Newly developed light-activation unit using blue light emitting diodes. Part 2: Effects of spectral distribution of SQW-LED on polymerization of resin composite. Jpn J Conserv Dent 1998; 41: 509-j16.

6) Small BW. A review of devices used for photocuring resin-based composites. Gen Dent 2001; 49: 457-460.

7) Mills RW, Jandt KD, Ashworth SH. Dental composite depth of cure with halogen and blue light emitting diode technology. Br Dent J 1999; 186: 388-391.

8) Matsumura H, Tanoue N, Atsuta M, Kitazawa S. A metal halide light source for laboratory curing of prosthetic composite materials. J Dent Res 1997; 76: 688-693.

9) Yamauti M, Senawongse P, Otsuki M, Tagami J. Initial bond strength of adhesive systems using four curing units. J Dent Res 2001; 30(Spec Issue): 588 Abstr\# 493.

10) Price RB, Derand T, Sedarous M, Andreou P, Loney RW. Effect of distance on the power density from two light guides. J Esthet Dent 2000; 12: 320-327.

11) Rueggeberg FA, Caughman WF, Curtis JW Jr, Davis
HC. Factors affecting cure at depths within lightactivated resin composites. Am J Dent 1993; 6: 91-95.

12) Prati C, Chersoni S, Montebugnoli L, Montanari G. Effect of air, dentin and resin-based composite thickness on light intensity reduction. Am J Dent 1999; 12(5): 231-234.

13) Yamauti $M$, Nikaido $T$, Harada $N$, Senawongse $P$, Otsuki M, Tagami J. Nanohardness of a bonding agent using four light curing units. J Dent Res 2003; 82(Special Issue C): C-635 Abstr \# 18.

14) DeWald JP, Ferracane JL. A comparison of four modes of evaluating depth of cure of light-activated composites. J Dent Res 1987; 66 (3): 727-730.

15) Ausiello P, Apicella A, Rengo S, Davidson CL. A 3D finite element analysis on the effect of adhesive layer properties on stress distribution in composite restorations. In: Clinical alternatives in restorative dentistry. Ed. Bertelli E, Ferrari M. March 2001.

16) Davidson CL, Davidson-Kaban SS. Handling of mechanical stresses in composite restorations. Dental Update 1998; 25: 274-279.

17) Pashley DH, Ciucchi B, Sano H, Carvalho RM, Russell $\mathrm{CM}$. Bond strength versus dentine structure: a modeling approach. Arch Oral Biol 1995; 40: 1109-1118.

18) Hansen SE, Swift EJ Jr. Microleakage with Gluma: effects of unfilled resin polymerization and storage time. Am J Dent 1989; 2: 266-268.

19) Crim GA. Pre-polymerization of Gluma 4 sealer: effect on bonding. Am J Dent 1990; 3: 25-27.

20) Cho BH, Dickens SH, Bae JH, Chang CG, Son HH, Um CM. Effect of interfacial bond quality on the direction of polymerization shrinkage flow in resin composite restoration. Oper Dent 2002; 27: 297-230.

21) Oliver WC, Pharr GM. An improved technique for determining hardness and elastic modulus using load and displacement sensing indentation experiments. J Mater Res 1992; 7(6): 1564-1583.

22) Ferracane JL. Correlation between hardness and degree of conversion during the setting reaction of unfilled dental restorative resins. Dent Mater 1985; 1(1): 11-14.

23) Van Meerbeek B, Willems G, Celis JP, Roos JR, Braem M, Lambrechts P, Vanherle G. Assessment by nanoindentation of hardness and elasticity of the resin-dentin bonding area. J Dent Res 1993; 72(10): 1434-1442.

24) Takahashi A, Sato $Y$, Uno S, Pereira PNR, Sano H. Effects of mechanical properties of adhesive resins on bond strength to dentin. Dent Mater 2002; 18: 263-268.

25) Habelitz S, Marshall GW Jr, Balooch M, Marshall SJ. Nanoindentation and storage of teeth. J Biomech 2002; 35: 995-998.

26) Kinney JH, Habelitz S, Marshall SJ, Marshall GW. The importance of intrafibrilar mineralization of collagen on mechanical properties of dentin. J Dent Res 2003; 82(12): 957-961.

27) Zheng L, Hilton JF, Habelitz S, Marshall SJ, Marshall GW. Dentin caries activity status related to hardness and elasticity. Eur J Oral Sci 2003; 111: 243-252.

28) Qin QH, Swain MV. A micro-mechanics model of 
dentin mechanical properties. Biomaterials 2004; 25: 5081-5090.

29) Fan PL, Stanford CM, Stanford WB, Leung R, Stanford JW. Effects of backing reflectance and mold size on polymerization of photo-activated composite resin. J Dent Res 1984; 63(10): 1245-1247.

30) Paul SJ, Leach M, Rueggeberg FA, Pashley DH. Effect of water content on the physical properties of model dentine primer and bonding resins. J Dent 1999; $27(3)$ : 209-214.

31) Carrilho MR, Carvalho RM, Tay FR, Pashley DH. Effects of storage media on mechanical properties of adhesive systems. Am J Dent 2004; 17(2): 104-108.

32) Hansen EK. After-polymerization of visible light activated resins: surface hardness vs. light source. Scand J Dent Res 1983; 91: 406-410.

33) Leung RL, Fan PL, Johnston WM. Post-irradiation polymerization of visible light-activated composite resin. J Dent Res 1983; 62: 363-365.

34) Musanje L, Darvell BW. Aspects of water sorption from the air, water and artificial saliva in resin composite restorative materials. Dent Mater 2003; 19(5): 414-422.

35) Rueggeberg FA, Caughman WF, Curtis JW Jr. Effect of light intensity and exposure duration on cure of resin composite. Oper Dent 1994; 19: 26-32.

36) Pires JA, Cvitko E, Denehy GE, Swift EJ Jr. Effects of curing tip distance on light intensity and composite resin microhardness. Quintessence Int 1993; 24(7): 517521.

37) Rueggeberg FA, Jordan DM. Effect of light tip distance on polymerization of resin composite. Int $\mathrm{J}$ Prosth 1993; 6: 364-370.

38) Christensen RP, Palmer TM, Ploeger BJ, Yost MP. Resin polymerization problems - are they caused by resin curing lights, resin formulations, or both? Compend Cont Educ Dent 1999; 20: S42-S54.

39) Burgess JO, Walker RS, Porche CJ, Rappold AJ. Light curing - an update. Compend Continn Educ Dent 2002; 23(10): 889-906.

40) Rueggeberg FA, Erle JW, Mettenburg DJ. Polymerization depths of contemporary light-curing units using microhardness. J Esthet Dent 2000; 12: 340-349.

41) Tanoue N, Matsumura H, Atsuta M. Curing depth of a composite veneering material polymerized with seven different laboratory photocuring units. J Oral Rehabil 1998A; 25: 199-203.

42) Tanoue N, Matsumura H, Atsuta M. Curing depth of four composite veneering materials polymerized with different laboratory photocuring units. J Oral Rehabil 1998B; 25: 348-352.

43) Fano L, Ma WY, Marcoli PA, Oizzi S, Fano V. Polymerization of dental composite resins using plasma light. Biomaterials 2002; 23: 1011-1015.

44) Gagliani, M, Fadini L, Ritzmann JM. Depth of cure efficacy of high-power curing devices vs. traditional halogen lamps. J Adhes Dent 2002; 4: 41-47.

45) Hofmann N, Hugo B, Schubert K, Klaiber B. Comparison between plasma arc light source and conventional halogen curing units regarding flexural strength, modulus, and hardness of photoactivated resin composites. Cli Oral Invest 2000; 4: 140-147.

46) Park SH, Krejci I, Lutz F. Microhardness of resin composites polymerized by plasma arc or conventional visible light curing. Oper Dent 2002; 27: 30-37.

47) Price RB, Derand T, Loney RW, Andreou P. Effect of light and specimen thickness on the surface hardness of resin composite. Am J Dent 2002; 15: 47-53.

48) Rueggeberg FA. Contemporary issues in photocuring. Compend Contin Educ Dent 1999; 20: S4-S15.

49) Sharkey S, Ray N, Burke F, Ziada H, Hannigan A. Surface hardness of light-activated resin composites cured by two different visible-light sources: an in vitro study. Quintessence Int 2001; 32: 401-405.

50) Jandt KD, Mills RW, Blackwell GB, Ashworth SH. Depth of cure and compressive strength of dental composites cured with blue light emitting diodes (LEDs). Dent Mater 2000; 16: 41-47.

51) Mills RW, Uhl A, Blackwell GB, Jandt KD. High power light emitting diode (LED) arrays versus halogen light polymerization of oral biomaterials: Barcol hardness, compressive strength and radiometric properties. Biomaterials 2002; 23: 2955-2963.

52) Dunn WJ, Bush AC. A comparison of polymerization by light-emitting diode and halogen-based light-curing units. J Am Dent Assoc 2002; 133: 335-341.

53) Knezevic A, Tarle Z, Meniga A, Sutalo J, Pichler G. Degree of conversion and temperature rise during polymerization of composite resin samples with blue diodes. J Oral Rehabil 2001; 28: 586-591.

54) Kurachi C, Tuboy AM, Magalhães DV, Bagnato VS. Hardness of a dental composite polymerized with experimental LED-based devices. Dent Mater 2000; 17: 309315.

55) Kemp-Scholte CM, Davidson CL. Complete marginal seal of Class $\mathrm{V}$ resin composite restorations effected by increased flexibility. J Dent Res 1990; 69(6): 1240-1243.

56) Van Meerbeek B, Vargas M, Inoue S, Yoshida $Y$, Perdigão J, Lambrechts P, Vanherle G. Microscopy techniques - Techniques, results, limitations. Am J Dent 2000; 13: 3D-18D.

57) Yoshida $Y$, Nagakane K, Fukuda R, Nakayama $Y$, Okazaki M, Shintani H, Inoue S, Tagawa Y, Suzuki K, De Munck J, Van Meerbeek B. Comparative study on adhesive performance of functional monomers. J Dent Res 2004; 83(6): 454-458.

58) Hotta M, Kondoh K, Kamemizu H. Effect of primers on bonding agent polymerization. J Oral Rehabil 1998; 25: 792-799.

59) Griffiths BM, Watson TF. Resin-dentin interface of Scotchbond multi-purpose dentin adhesive. Am J Dent 1995; 8: 212-216.

60) Nikaido T, Nagata K, Nakabayashi N. Photocurable bonding liner for teeth. Part III: Effect of Nphenylglycine. J Jpn Soc Dent Mater Dev 1988; 7(3): 466-470.

61) Nikaido T, Podszun W, Muller M, Nakabayashi N. Effect of sulfonamides and 4-MET on adhesion to tooth substrates. Dent Mater 1990; 6(2): 78-82.

62) Hirabayashi C, Imai Y. Studies on MMA-tBB resin. 
Part I: Comparison of TBB and other initiators in the polymerization of PMMA/MMA resin. Dent Mater J 2002; 21 (4): 314-321.

63) Hirabayashi C. Studies on MMA-TBB resin. Part II:
The effect of dual use of TBB and other initiators on polymerization of PMMA/MMA resin. Dent Mater J 2003; $22(1)$ : 48-55. 